\title{
Effects of Pasture on Lameness in Dairy Cows
}

\author{
O. Hernandez-Mendo, ${ }^{*}$ M. A. G. von Keyserlingk, $†$ D. M. Veira,‡ and D. M. Weary $\dagger^{1}$ \\ *Especialidad de Ganadería, Colegio de Postgraduados, Montecillos, Texcoco, Mexico 56230 \\ †Animal Welfare Program, Faculty of Food and Land Systems, The University of British Columbia, Vancouver, British Columbia, Canada \\ $\ddagger$ Agriculture and Agri-Food Canada, Pacific Agri-Food Research Centre, PO Box 1000, Agassiz, British Columbia, Canada V0M 1AO
}

\begin{abstract}
This study tested whether providing cows a 4-wk period on pasture would improve gait and change lying behavior. Eighteen groups, each of 4 lactating Holstein cows initially housed in a freestall barn, were assigned to either continued housing in the same freestall barn, or moved to pasture to provide changes in both physical environment and diet. To assess lameness, gait scores (1 to 5 ) were recorded weekly for $4 \mathrm{wk}$. Gait improved by an average of 0.22 units/wk for those cows kept on pasture. We also recorded 4 specific gait attributes (head bob, back arch, tracking up, and reluctance to bear weight evenly on all 4 hooves), and found that the latter 2 attributes also improved during the pasture period. Improved gait for cows on pasture was not because of increased lying times. Cows on pasture actually spent less time lying down than cows kept indoors $(10.9$ vs. $12.3 \mathrm{~h} / \mathrm{d}$ ), although this lying time was spread over a larger number of bouts (15.3 vs. 12.2 bouts). Cows housed on pasture also lost more weight and produced less milk relative to cows in freestalls, likely because of reduced nutrient intake. These results indicate that a period on pasture can be used to help lame cattle recover probably because pasture provides a more comfortable surface upon which cows stand, helping them to recover from hoof and leg injuries.
\end{abstract}

Key words: gait score, lameness, housing, behavior

\section{INTRODUCTION}

Lameness is one of the major problems of intensive dairy production, as well as a cause of pain and discomfort for dairy cows (Whay et al., 1997). Freestall housing systems are designed for ease of management, but are associated with a greater risk of hoof injuries and disease leading to lameness (Faye and Lescourret, 1989; Somers et al., 2003). Pasture rearing can improve hoof health, perhaps due to the change in the physical environment per se, or to associated factors such as change

Received March 3, 2006.

Accepted October 30, 2006.

${ }^{1}$ Corresponding author: danweary@interchange.ubc.ca in diet. Incidence of lameness is reported to be less during the grazing season (Leaver, 1988), and cows kept indoors have a greater prevalence of claw disorders and lameness than those that are allowed to graze (Smits et al., 1992; Gitau et al., 1996). Despite these advantages in hoof health, switching from indoor housing to pasture is not a practical option for many producers. Providing a rest period on pasture for lame cows may be more feasible, but to date no work has documented how lame cows respond to the change from indoor housing to pasture.

Locomotion scoring systems are useful in assessing severity, duration, and prevalence of lameness, and are normally based on descriptions of body posture and gait. Well-known examples are the systems developed by Sprecher et al. (1997) and Manson and Leaver (1988). Both used scores ranging from 1 to 5 to reflect increased severity of lameness. Lameness scoring typically involves the subjective assessment of a number of gait attributes, such as extent of back arch and reluctance to bear weight evenly across the 4 feet. Recently, Flower and Weary (2006) showed that some of these specific gait attributes could be recorded consistently and were useful in distinguishing among cows with and without sole ulcers. No work to date has attempted to determine how these individual gait characteristics respond to a period of treatment.

One reason cows may benefit from pasture is that it may be a more comfortable surface for either lying down or upon which to stand. A number of recent studies have identified a relationship between lameness and comfortable housing for dairy cows (Vokey et al., 2001; Cook, 2003). Comfortable housing may improve hoof health by providing a more appropriate surface for standing (Tucker et al., 2006a), or by providing cows a more comfortable area on which to lie down (Cook et al., 2004).

The primary objective of this study was to test whether a relatively short period on pasture would improve the gait of lame cows, and to determine which elements of gait are most affected by this treatment. Time on pasture may reduce lameness of cows by providing access to more comfortable standing and lying surfaces. Thus, a secondary objective was to determine 
how pasture rearing affects lying behavior in dairy cows.

\section{MATERIALS AND METHODS}

\section{Cows and Treatments}

The experiment was carried out from July 4 to October 20, 2004, using 72 multiparous, Holstein cows in mid to late lactation from the University of British Columbia Dairy Education and Research Centre. All cows had been housed in the same freestall barn since the end of their dry period.

Before starting the experiment, cows were gait scored using a system described by Flower and Weary (2006). Cows were assigned using a numerical rating system score (NRS) ranging from 1 to 5 in 0.5 -point increments. A score of 1 reflected sound cows, showing a flat back and steady head carriage, with hind hooves falling in or near the tracks left by the front hooves, joints flexing freely, symmetrical gait, and all legs seeming to bear weight equally. A score of 5 was assigned to severely lame cows, showing a distinct back arch and head bob, poor tracking-up and joint flexion, asymmetric gait, and an obvious limp (i.e., a reluctance to bear weight equally on all limbs). The NRS has been shown to be a valid indicator of known hoof injuries (sole ulcers) and to be applicable with high levels of inter- and intraobserver reliability (Flower and Weary, 2006).

Cows were assigned to groups of 4 each based on gait score, such that each group contained at least 1 cow having scores of $2.5,3$, and 3.5. The fourth cow could have any of these 3 scores, but during each replicate, this too, was balanced such that average gait score for both treatments was 3 . Groups were assigned randomly to be housed on pasture condition or to remain in the same freestall barn. Groups were balanced for DIM $(237 \pm 43)$, parity $(3.4 \pm 1.9)$, daily milk production $(33.4 \pm 4.8 \mathrm{~kg})$, and BW $(715 \pm 75 \mathrm{~kg})$. Each group was managed separately, and groups were monitored for 4 wk after they were initially gait scored and assigned to treatment. Six groups (3 per treatment) were monitored at any one time, with 18 groups observed ( 9 per treatment). Hoof health and condition were not assessed directly in this study. Hooves of cows were last trimmed during their most recent dry period.

\section{Housing and Management}

Freestall. Each group of freestall-housed cows was kept in a pen together with 8 nonexperimental cows. Pens had $6 \mathrm{~m}$ of accessible feed alley space and 12 freestalls filled with $40 \mathrm{~cm}$ of washed river sand. In each pen, the 12 stalls were configured in 3 rows. Two rows faced one another, were open at the front, and had a length of $240 \mathrm{~cm}$. The back row faced a cement wall and had a length of $270 \mathrm{~cm}$; all stalls were 110 $\mathrm{cm}$ wide. The cross-over alleys were scraped manually twice daily, and all other alleys were cleaned 6 times daily with automatic scrapers. All flooring outside the freestall area was grooved concrete. Cows were away from the pen for approximately $30 \mathrm{~min}$ for each milking. The morning milking started between 0600 and 0700 $\mathrm{h}$ and the afternoon milking started between 1530 and $1630 \mathrm{~h}$.

Cows were fed ad libitum a TMR consisting of $17.7 \%$ corn silage, $19.5 \%$ grass silage, $33.6 \%$ corn/barley blend, $5.6 \%$ alfalfa hay, $3.6 \%$ grass hay, and $20.0 \%$ concentrate mash on a DM basis. The composition of the TMR was $47.7 \% \mathrm{DM}$ and contained (on a DM basis) $18.1 \% \mathrm{CP}$, $35 \% \mathrm{NDF}, 18.7 \% \mathrm{ADF}, 0.9 \% \mathrm{Ca}$, and $0.5 \%$ P. Fresh feed was provided twice daily at 0500 and $1500 \mathrm{~h}$, and feed was pushed up at 1100 and $2300 \mathrm{~h}$. Water was available ad libitum from a self-filling trough located in the crossover alley of each pen. Cows were walked 120 to 160 $\mathrm{m}$ (round trip) on grooved concrete from their pens to the milking parlor, with distance depending upon the location of the home pen.

Pasture. The 24-ha grazing area consisted of "Profile" orchard grass (Dactylis glomerata) and festuolium (tall fescue $\times$ ryegrass cross) seeded 3 yr earlier. Simulated (plucked) grazing samples of the mixed grass stand contained $23.4 \% \mathrm{DM}$ that was composed of $22.9 \%$ $\mathrm{CP}, 27.1 \% \mathrm{ADF}, 0.6 \% \mathrm{Ca}, 3.38 \% \mathrm{~K}$, and $0.3 \% \mathrm{P}$. The field was divided into 4 paddocks of 6 ha each and each paddock was divided into 3 subpaddocks used to house groups of 12 cows (4 experimental and 8 nonexperimental cows). A strip grazing system was used with cows moved to a new strip every $24 \mathrm{~h}$. Cows were kept continuously on pasture at all times except when moved to the parlor for milking and feed supplementation. When moved to the parlor, cows were walked along a $4 \mathrm{~m}$ wide dirt track at their own speed. The track was checked for sharp stones and foreign objects twice daily. The roundtrip distance cows were walked varied from $140 \mathrm{~m}$ to $1.1 \mathrm{~km}$ depending upon which pasture they grazed.

Each cow was given $6 \mathrm{~kg}$ of concentrate $(78.2 \% \mathrm{DM}$, $3.4 \%$ fat, $15.0 \% \mathrm{CP}, 9.1 \% \mathrm{ADF}$, and $24 \% \mathrm{NDF}$ ) twice daily from individual plastic bins on their return from the parlor, but before going back to pasture. All cows had free access to water from troughs available in each paddock. Cows were milked between 0730 and 0800 $\mathrm{h}$ in the morning and between 1500 and $1530 \mathrm{~h}$ in the afternoon.

\section{Measurements}

Body weight was measured weekly. Milk yield was recorded daily and averaged to provide a weekly average per cow. 
All cows were videotaped weekly immediately after the morning milking. Cows were walked down a $1.2-\times$ 40-m grooved concrete corridor. Individual cows were assigned an NRS as described above. In addition, 4 specific gait attributes (back arch, head bob, tracking up, and reluctance to bear weight) were measured using a visual analogue scale by assigning a mark on a continuous 100-unit scale, where 0 represented completely sound and 100 represented the most extreme condition (Flower and Weary, 2006). Following the recommendations of the previous study (Flower and Weary, 2006), 2 other gait attributes (joint flexion and asymmetric steps) were not assessed because of poor intraobserver repeatability. Video clips were all scored by a single trained observer, blind to treatment.

Number of lying bouts and total time spent lying down were measured for all cows during the entire experimental period using data loggers (Tinytag Plus, Gemini Inc., Chichester, UK). Data loggers were attached to the rear leg on the day before data collection began and recorded posture (standing or lying) once per minute throughout the collection period. Every $7 \mathrm{~d}$, data were downloaded and loggers were switched to the contralateral leg. No records were available to determine where the cows were standing and lying, but in the barn, cows were never observed lying down outside of the stall.

\section{Statistical Analysis}

Changes in gait from the baseline observation until the end of the trial were estimated separately for each cow using the slope from a least squares regression. Because housing treatments were assigned to replicate groups, effect of housing ( $1 \mathrm{df}$ ) was tested using group as the error term ( $8 \mathrm{df}$ ) in a generalized linear model. Cows within group varied in their initial gait score, so this variable ( $1 \mathrm{df})$ and the interaction between initial gait score and housing ( $1 \mathrm{df}$ ), were included in the same model, but tested against the residual error (60 df). Changes in BW and daily milk yield were analyzed by using the same model.

Lying time and number of lying bouts were measured daily during the trial, but preliminary analysis showed no consistent changes during the study. Therefore, the daily estimates were averaged to generate 1 mean value for per cow. These means were analyzed in the same model as described above for change in gait score.

\section{RESULTS}

Cows on pasture lost more $(P=0.014)$ weight than those kept indoors (decrease of $2.6 \mathrm{~kg} / \mathrm{wk}$ vs. increase of $0.5 \mathrm{~kg} / \mathrm{wk} ; \mathrm{SEM}=0.88$ ). Milk production of cows in

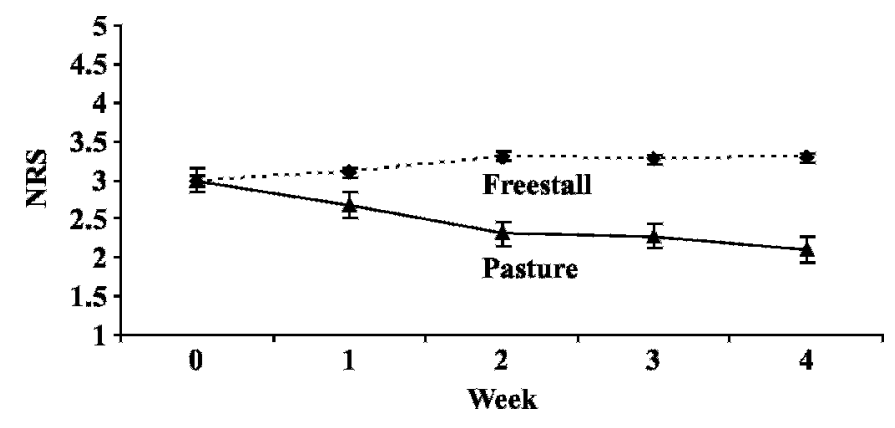

Figure 1. Changes in numerical rating system score (NRS; \pm SE) for dairy cows kept on pasture or in a freestall barn ( $n=9$ groups of cows per treatment).

both treatments decreased during the trial, but this decrease $(P<0.001)$ was greater for the cow kept on pasture $(1.7 \pm 0.16 \mathrm{~kg} / \mathrm{wk})$ than for freestall cows $(0.7$ $\pm 0.16 \mathrm{~kg} / \mathrm{wk})$.

By design, average NRS for both treatments was 3.0 at the beginning of the experiment. Gait tended to be stable or to worsen during the trial for cows kept in the freestall barn, but gait improved $(P<0.001)$ for those cows on pasture (Figure 1). The NRS for cows on pasture improved by 0.22 units/wk, such that NRS for the 2 treatments differed by more than 1 unit at the end of the trial.

Baseline values for all gait measures, together with how these changed during the trial, are provided in Table 1. On average, each of the individual gait components improved $(P \leq 0.05)$ for cows on pasture (as indicated by the negative slopes in Table 1). In particular, reluctance to bear weight showed considerable improvement $(P \leq 0.001)$ for groups kept on pasture. Trackingup also improved $(P \leq 0.05)$ for the groups kept on pasture, although the magnitude of improvement was much less. The difference between treatment conditions was only of borderline significance $(P=0.06)$ for back arch and was not significant for head bob.

Table 1. Initial scores and changes in behaviors during the 4-wk period between the pasture and freestall treatments $(n=9$ replicate groups per treatment)

\begin{tabular}{lccccc}
\hline & \multirow{2}{*}{$\begin{array}{c}\text { Initial } \\
\text { Vcore }\end{array}$} & Pasture & Freestall & & Slope \\
\cline { 3 - 4 } & SEM & $P$ \\
\hline NRS & 3.0 & -0.22 & 0.08 & 0.021 & 0.001 \\
Back arch & 26 & -1.2 & 0.2 & 0.38 & 0.059 \\
Head bob & 4 & -0.6 & 0.4 & 0.28 & 0.112 \\
Tracking-up & 8 & -0.6 & 0.6 & 0.36 & 0.016 \\
RBW & 14 & -2.3 & 1.6 & 0.42 & 0.001 \\
\hline
\end{tabular}

${ }^{1} \mathrm{NRS}=$ numerical rating system score; RBW = reluctance to bear weight.

${ }^{2}$ Negative slopes (least squares mean \pm SEM of slope) indicate that the gait attribute improved over time. 
An interaction was detected $(P<0.05)$ between treatment and baseline gait score for reluctance to bear weight. Cows with the greatest initial gait scores showed the greatest improvement when kept on pasture.

Cows on pasture spent less $(P<0.01)$ time lying down than cows housed in the freestall barn (10.9 vs. $12.3 \mathrm{~h} /$ $\mathrm{d}$; SEM $=0.3)$. In addition, cows on pasture lay down more $(P<0.001)$ often than cows kept indoors $(15.3 \mathrm{vs.}$ 12.2 lying bouts/d; SEM $=0.3$ ).

\section{DISCUSSION}

The current study showed that gait improved during a 4-wk period when lame cows were kept on pasture. By the end of the study, cows on pasture had an average NRS close to 2 , but those in freestalls scored more than 3 , where 3 or more is considered to be clinically lame.

Whether this improvement in gait was because of improvements in hoof health cannot be addressed directly because hoof health was not measured in the current study. It has been suggested that more than $90 \%$ of lameness cases are caused by hoof lesions (Bergsten, 2001). A number of previous studies have shown that access to pasture improves hoof health in lactating dairy cattle (Somers et al., 2003). Recent work (Flower and Weary, 2006) has begun to illustrate the relationship between hoof health and cow gait. Some serious problems in hoof health, such as the presence of sole ulcers, have clear effects on the gait measures used in the current study. Other ailments such as sole hemorrhages are not clearly associated with changes in gait; some cows have visible injuries but show normal gait, and others are clinically lame but have no visible hoof ailments (Flower and Weary, 2006). This poor correlation may occur in part because of the lag between the time that hoof ailments can be scored and when gait is disrupted. It is also possible that some changes in gait are not associated with hoof health.

Improvements in gait observed in our study may have occurred partly because of changes in joint stiffness. It has been suggested that concrete floors do not provide sufficient friction, causing slipping and resulting in cows walking with a "stiff" gait (van der Tol et al., 2005). Phillips and Morris (2000, 2001) also suggested that concrete flooring is associated with a smaller range of joint motion. Concrete flooring in freestall barns is often covered with manure slurry. van der Tol et al. (2005) reported that slippage doubles on slurry-covered concrete compared with dry surfaces, so cows habituated to slurry-covered concrete may be particularly stiff. Work in humans shows that joint stiffness also results from limited amounts of activity (Mansour and Audu, 1987), indicating that improvements among cows on pasture may have been caused by increased general exercise by these cows. Pastured cows are required to spend more time walking because of grazing and the increased distance to the parlor. Although some previous studies have examined the relationship between exercise and lying behavior and hoof health (Gustafson, 1993; Loberg et al., 2004), we are not aware of research that has directly assessed the effects of exercise on gait in cattle and we encourage new research in this area.

In addition to changes in the NRS, we also documented how specific aspects of gait changed during the study. To our knowledge this is the first such test of the effects of housing systems on specific gait attributes. Reluctance to bear weight proved to be particularly sensitive to treatment, with cows on pasture seeming to distribute their weight more evenly on all legs by the end of the study. We observed a more modest improvement in tracking-up, but the pasture treatment had little effect on 2 other attributes (back arch and head bob) thought to be indicators of lameness. Flower and Weary (2006) also found that these latter 2 gait attributes were less useful in separating cows having sole ulcers. Together these results indicate that back arch and head bob are of more limited value in identifying lameness. They also indicated that new work on quantitative assessments of weight bearing might be particularly promising.

In our study, groups of cows kept on pasture spent considerably less time lying down than did those kept in freestalls, averaging 10.9 and $12.3 \mathrm{~h} / \mathrm{d}$, respectively. The values reported here are very similar to other recent studies for cows in freestalls (Cook et al., 2004). Although lying times were less on pasture, the average lying time for pastured cows in our study was still greater than that reported in previous work. For example, lying times of just 6 to $7 \mathrm{~h} / \mathrm{d}$ for lactating cows on pasture were reported (Hassall et al., 1993; Singh et al., 1993). Greater lying times in the current study may have been the result of better pasture quality or because the supplemental feed provided reduced grazing times (Phillips and Leaver, 1986). Feed is usually provided centrally in a feed alley for cows housed indoors, but pastured cows must spend time walking to search for food, particularly under poor grazing conditions. Hernandez-Mendo and Leaver (2004) showed that when the availability of herbage was limited, dairy cows increased their grazing time and reduced the time spent lying down.

A series of recent studies has shown that cows spend more time lying down in areas with fewer physical restrictions (such as in freestalls without brisket boards; Tucker et al., 2006b), indicating that cows should have spent more recumbent time on open pasture. Effect of lying surface is also important in determining lying 
times; cows prefer to spend more time lying down on softer surfaces and surfaces that are well bedded (Cook et al., 2004). Interestingly, the number of lying bouts was greater for groups on pasture ( $15 \mathrm{vs.} 12$ per d) than for those in freestalls, such that average duration of lying bouts was considerably shorter for the pastured cows. Previous work on cow comfort has shown that the reduction in lying time on less comfortable surfaces is driven by fewer lying bouts, and not the duration of the lying bout (Tucker and Weary, 2004). The inconsistency in the pattern observed in the current study (shorter total lying times, but more lying bouts) compared with other work on cow comfort indicates that the reduced lying time on pasture was not because of its lack of comfort as a lying surface.

Cows also may have found the pasture a more comfortable surface for standing. The majority of research on cow comfort has concentrated on the suitability of stalls for lying, but cows also spend a considerable portion of their day standing inside and outside of the freestall. Freestalls are designed to prevent standing in the stall, with the neck rail placed to encourage cows to lie down when they enter the stall. Some cows can still stand in the stalls, but stalls with more restrictive neck-rail placement reduce this standing time (Tucker et al., 2005). On pasture, cows lie down and stand on the same surface, but in freestall barns, cows may use the stalls as a refuge from standing on uncomfortable concrete surfaces elsewhere in the barn. Two recent studies (Fregonesi et al., 2004; Tucker et al., 2006a) have shown that providing more comfortable flooring elsewhere in the barn increases standing times on those surfaces and decreases stall usage, especially for lying. Thus, the reduced lying time for cows on pasture may have been because cows prefer to spend time standing on this surface. In addition, cows on pasture did not have access to shade, and thus, were likely at increased risk of thermal stress on warm summer days. Under these conditions, standing may be more attractive to cows as this posture facilitates heat dissipation (Juarez et al., 2003).

Given the range of factors that can affect how cows respond to both pasture and indoor housing, we urge caution in extrapolating the results from the current study to other situations. It is possible that sufficiently well designed indoor housing, or sufficiently poor conditions on pasture, could reduce or reverse the effects we report herein. Indeed, it is an aim of our research to continue to improve indoor housing conditions such that the incidence of lameness and other health problems is reduced.

Although this discussion has focused on how pasture may affect cow comfort, pasture rearing also exposes cows to a change in diet, and this too may have affected the cows. Our results showed that the pasture cows lost more weight and reduced milk yield relative to freestall cows. Although concentrate was provided to cows on pasture, the decreased nutrient density of the grass consumed on pasture (relative to the TMR consumed by the freestall cows) was expected to reduce energy intake of pastured cows, accounting for the changes in BW and milk yield. The magnitude of such changes will, of course, vary in relation to grazing conditions and feed management (Hernandez-Mendo and Leaver, $2002,2004)$. In the current study it was impossible to determine if the changes in gait were caused in part by these differences in diet; however, previous research has shown that housing conditions and diet can affect hoof health (Webster, 2001).

In conclusion, gait scores improved during a 4 -wk period on pasture. The positive effects on hoof health of longer term pasture rearing are well documented, but this study now provides evidence that lame cows can show rapid improvements in gait during a relatively short time on pasture. Further studies are needed to determine if these gait improvements are because of improvements in hoof health, and to determine if cows continue to benefit once they have returned to indoor housing. Experimental work is also warranted to determine if changes in flooring surfaces and other improvements in barn design might provide similar advantages for indoor-housed cattle (Webster, 2002).

\section{ACKNOWLEDGMENTS}

We gratefully acknowledge the staff and students at The University of British Columbia's Dairy Education and Research Centre and the University's Animal Welfare Program, and especially Frances Flower and Cassandra Tucker for their insights. The project was funded by the Natural Sciences and Engineering Research Council of Canada, through the Industrial Research Chair in Animal Welfare, and by contributions from the Dairy Farmers of Canada, the BC Dairy Foundation, the BC SPCA, members of the BC Veterinary Medical Association, and many other donors listed on the Animal Welfare website at http://www.landfood. ubc.ca/animalwelfare.

\section{REFERENCES}

Bergsten, C. 2001. Effects of conformation and management system on hoof and leg diseases and lameness in dairy cows. Vet. Clin. North Am. Food Anim. Pract. 17:1-23.

Cook, N. B. 2003. Prevalence of lameness among dairy cattle in Wisconsin as a function of housing type and stall surface. J. Am. Vet. Med. Assoc. 223:1324-1328.

Cook, N. B., T. B. Bennet, and K. V. Nordlund. 2004. Effect of free stall surface on daily activity patterns in dairy cows, with relevance to lameness prevalence. J. Dairy Sci. 87:2912-2922. 
Faye, B., and F. Lescourret. 1989. Environmental factors associated with lameness in dairy cattle. Prev. Vet. Med. 7:267-287.

Flower, F. C., and D. M. Weary. 2006. Effect of hoof pathologies on subjective assessments of dairy cow gait. J. Dairy Sci. 89:139-146.

Fregonesi, J. A., C. B. Tucker, D. M. Weary, F. C. Flower, and T. Vittie. 2004. Effect of rubber flooring in front of the feed bunk on the behavior of dairy cattle. J. Dairy Sci. 87:1203-1207.

Gitau, T., J. J. McDermott, and S. M. Mbiuki. 1996. Prevalence, incidence and risk factors for lameness in dairy cattle in small scale farms in Kikuyu Division, Kenya. Prev. Vet. Med. 28:101-115.

Gustafson, G. M. 1993. Effects of daily exercise on the health of tied dairy cows. Prev. Vet. Med. 17:209-223.

Hassall, S. A., W. R. Ward, and R. D. Murray. 1993. Effects of lameness on the behaviour of cows during the summer. Vet. Rec. 132:578-580.

Hernandez-Mendo, O., and J. D. Leaver. 2002. Feed maize silage to increase body reserves in grazing dairy cows. Pages $31-35$ in The British Grassland Society (BGS) winter meeting. S. Peel, ed. The BGS and University of Reading, Reading, UK.

Hernandez-Mendo, O., and J. D. Leaver. 2004. Effect of replacing time available for grazing with time available for eating maize silage and soybean meal on milk yield and feeding behaviour in dairy cows. Grass Forage Sci. 59:318-330.

Juarez, S. T., P. H. Robinson, E. J. Depeters, and E. O. Price. 2003. Impact of lameness on behavior and productivity of lactating Holstein cows. Appl. Anim. Behav. Sci. 83:1-14.

Leaver, J. D. 1988. Management and welfare of Animals. 3rd ed. Bailliere Tindall, London, UK.

Loberg, J., E. Telezhenko, C. Bergsten, and L. Lidfors. 2004. Behaviour and claw health in tied cows with varying access to exercise in an outdoor paddock. Appl. Anim. Behav. Sci. 89:1-16.

Manson, F. J., and J. D. Leaver. 1988. The influence of concentrate amount on locomotion and clinical lameness in dairy cattle. Anim. Prod. 47:185-190.

Mansour, J. M., and M. L. Audu. 1987. Passive elastic moment at the knee and its influence on human gait. J. Biomech. 19:51-58.

Phillips, C. J. C., and J. D. Leaver. 1986. The effect of forage supplementation on the behavior of grazing dairy cows. Appl. Anim. Behav. Sci. 16:233-248.

Phillips, C. J. C., and I. D. Morris. 2000. The locomotion of dairy cows on concrete floors that are wet, dry or covered with slurry of excreta. J. Dairy Sci. 83:1767-1772.
Phillips, C. J. C., and I. D. Morris. 2001. The locomotion of dairy cows on floor surfaces with different frictional properties. J. Dairy Sci. 84:623-628.

Singh, S. S., W. R. Ward, K. Lautenbach, J. W. Hughes, and R. D. Murray. 1993. Behaviour of first lactation and adult dairy cows while housed and at pasture and its relationship with sole lesions. Vet. Rec. 133:469-474.

Smits, M. C. J., K. Frankena, J. H. M. Metz, and J. P. T. M. Noordhuizen. 1992. Prevalence of digital disorders in zero-grazing dairy farms. Livest. Prod. Sci. 32:231-244.

Somers, J. G. C. J., K. Frankena, E. N. Noordhuizen-Stassen, and J. H. M. Metz. 2003. Prevalence of claw disorders in Dutch dairy cows exposed to several floor systems. J. Dairy Sci. 86:2082-2093.

Sprecher, D. J., D. E. Hostetler, and J. B. Kaneene. 1997. A lameness scoring system that uses posture and gait to predict dairy cattle reproductive performance. Theriogenology 47:1179-1187.

Tucker, C. B., and D. M. Weary. 2004. Bedding on geotextile mattresses: How much is needed to improve cow comfort? J. Dairy Sci. 87:2889-2895.

Tucker, C. B., D. M. Weary, and D. Fraser. 2005. Influence of neckrail placement on free-stall preference, use and cleanliness. J. Dairy Sci. 88:2730-2737.

Tucker, C. B., D. M. Weary, A. M. de Passillé, B. Campbell, and J. Rushen. 2006a. Type of flooring in front of the feed bunk affects feeding behavior and use of freestalls by dairy cows. J. Dairy Sci. 89:2065-2071.

Tucker, C. B., D. M. Weary, and M. Zdanowicz. 2006b. Brisket boards reduce freestall use. J. Dairy Sci. 89:2603-2607.

van der Tol, P. P. J., J. H. M. Metz, E. N. Noordhuizen-Stassen, W. Back, C. R. Braam, and W. A. Weijs. 2005. Frictional forces required for unrestrained locomotion in dairy cattle. J. Dairy Sci. 88:615-624.

Vokey, F. J., C. L. Guard, and D. M. Galtan. 2001. Effects of alley and stall surfaces on indices of claw and leg health in dairy cattle housed in a free-stall barn. J. Dairy Sci. 84:2686-2699.

Webster, A. J. F. 2001. Effects of housing and two forage diets on the development of claw horn lesions in dairy cows at first calving and first lactation. Vet. J. 162:56-65.

Webster, A. J. F. 2002. Effects of housing practices on the development of foot lesions in dairy heifers in early lactation. Vet. Rec. 151:9-12.

Whay, H. R., A. E. Waterman, and A. J. F. Webster. 1997. Associations between locomotion, claw lesions and nociceptive threshold in dairy heifers during the peri-partum period. Vet. J. 154:155-161. 